\title{
Liquid Scoping Study for Tritium-Lean, Fast Ignition Inertial Fusion Energy Power Plants
}

R.C. Schmitt, J.F. Latkowski, S.G. Durbin, W.R. Meier, S. Reyes

\section{August 14, 2001}

U.S. Department of Energy

Lawrence

Livermore

National

Laboratory 


\section{DISCLAIMER}

This document was prepared as an account of work sponsored by an agency of the United States Government. Neither the United States Government nor the University of California nor any of their employees, makes any warranty, express or implied, or assumes any legal liability or responsibility for the accuracy, completeness, or usefulness of any information, apparatus, product, or process disclosed, or represents that its use would not infringe privately owned rights. Reference herein to any specific commercial product, process, or service by trade name, trademark, manufacturer, or otherwise, does not necessarily constitute or imply its endorsement, recommendation, or favoring by the United States Government or the University of California. The views and opinions of authors expressed herein do not necessarily state or reflect those of the United States Government or the University of California, and shall not be used for advertising or product endorsement purposes.

This is a preprint of a paper intended for publication in a journal or proceedings. Since changes may be made before publication, this preprint is made available with the understanding that it will not be cited or reproduced without the permission of the author.

This report has been reproduced directly from the best available copy.

Available electronically at http://www.doe.gov/bridge

Available for a processing fee to U.S. Department of Energy and its contractors in paper from

U.S. Department of Energy

Office of Scientific and Technical Information

P.O. Box 62

Oak Ridge, TN 37831-0062

Telephone: (865) 576-8401

Facsimile: (865) 576-5728

E-mail: reports@adonis.osti.gov

Available for the sale to the public from

U.S. Department of Commerce

National Technical Information Service

5285 Port Royal Road

Springfield, VA 22161

Telephone: (800) 553-6847

Facsimile: (703) 605-6900

E-mail: orders@ntis.fedworld.gov

Online ordering: http://www.ntis.gov/ordering.htm

OR

Lawrence Livermore National Laboratory

Technical Information Department's Digital Library

http://www.llnl.gov/tid/Library.html 


\title{
Liquid Scoping Study for Tritium-Lean, Fast Ignition Inertial Fusion Energy Power Plants*
}

\author{
R. C. Schmitt ${ }^{1,2}$, J. F. Latkowski ${ }^{2}$, S. G. Durbin ${ }^{3}$, W. R. Meier $^{2}$, S. Reyes ${ }^{2}$ \\ ${ }^{1}$ University of Michigan-Ann Arbor, Department of Nuclear Engineering \\ ${ }^{2}$ Lawrence Livermore National Laboratory \\ P. O. Box 808, Mailstop L-632 \\ Livermore, CA 94550
}

${ }^{3}$ Georgia Institute of Technology, Department of Mechanical Engineering

\begin{abstract}
In a thick-liquid protected chamber design, such as HYLIFE-II, a molten-salt is used to attenuate neutrons and protect the chamber structures from radiation damage. The molten-salt absorbs some of the material and energy given off by the target explosion. In the case of a fast ignition inertial fusion system, advanced targets have been proposed that may be self-sufficient in the tritium breeding (i.e., the amount of tritium bred in target exceeds the amount burned). These "tritium-lean" targets contain approximately $0.5 \%$ tritium and $99.5 \%$ deuterium, but require a large pr of $10-20 \mathrm{~g} / \mathrm{cm}^{2}$. Although most of the yield is provided by D-T reactions, the majority of fusion reactions are D-D, which produces a net surplus of tritium. This aspect allows for greater freedom when selecting a liquid for the protective blanket (lithium-bearing compounds are not required).
\end{abstract}

This study assesses characteristics of many single, binary, and ternary molten-salts. Using the NIST Properties of Molten Salts Database, approximately 4300 molten-salts were included in the study [1]. As an initial screening, salts were evaluated for their safety and environmental (S\&E) characteristics, which included an assessment of waste disposal rating, contact dose, and radioactive afterheat. Salts that passed the S\&E criteria were then evaluated for neutron shielding ability and pumping power. The pumping power was calculated using three components: velocity head losses, frictional losses, and lift.

This assessment left us with 57 molten-salts to recommend for further analysis. Many of these molten-salts contain elements such as sodium, lithium, beryllium, boron, fluorine, and oxygen. Recommendations for further analysis are also made.

* This work was performed under the auspices of the U.S. Department of Energy by the University of California, Lawrence Livermore National Laboratory under contract No. W-7405-Eng-48. 


\section{Table of contents}

1. Introduction 4

2. Safety and Environmental Characteristics Assessment 6

a. Waste Disposal Rating $\quad 6$

b. Radioactive Afterheat 7

c. Contact Dose Rate $\quad \mathbf{8}$

3. Pumping Power Assessment 9

a. Velocity Head 10

b. Frictional/Minor Losses 11

c. Lifting Power 12

4. Conclusions and Recommendations 15

5. Acknowledgements 16

6. References 16 


\section{Introduction}

The idea of inertial fusion using fast-ignition has been proposed as a method of achieving relatively high gain using ultra-powerful lasers to ignite the fusion fuel [2]. Advanced targets have also been proposed that may be self-sufficient in the tritium breeding aspect. These "tritium-lean" targets contain approximately $0.5 \%$ tritium and $99.5 \%$ deuterium (see Fig. 1.1), but require a large $\rho$ r of $10-20 \mathrm{~g} / \mathrm{cm}^{2}$ (compared to $\sim 3 \mathrm{~g} / \mathrm{cm}^{2}$ for conventional hot-spot ignition. About $55 \%$ of the energy released by S. Atzeni's target is produced by D-T reactions, even though the majority $(60.5 \%)$ of the reactions are D-D, which produces a new surplus of tritium $[2,3,4]$. Table 1.1 shows the tritium balance within a tritium-lean target [3]. Figure 1.3 shows the spectrum from Atzeni's "tritiumlean" fusion target. In order to achieve $1 \mathrm{GW}$ power plant output, and because of the large yield $(1330 \mathrm{MJ})$, these targets will be ignited at a frequency of $1.7 \mathrm{~Hz}$. The low repetition keeps the pumping power significantly lower than in a traditional $5-10 \mathrm{~Hz}$ system. These targets may be direct or indirectly driven, and Figure 1.2 shows a schematic of a potential setup for both systems.

\section{Tritium Balance Within a Tritium-Lean Target}

- Initial tritium loading $=0.53 \%$ in $19.6 \mathrm{mg}$

$=156 \mu \mathrm{g}$

$=3.11 \times 10^{19}$ tritons

- Fusion reactions:

\# of D-D fusions $\quad=5.01 \times 10^{20}$ per target $\left(2.51 \times 10^{20}\right.$ tritons created $)$

\# of D-T fusions $\quad=2.58 \times 10^{20}$ per target $\left(2.58 \times 10^{20}\right.$ tritons destroyed $)$

\# of $\mathrm{D}^{-}{ }^{3} \mathrm{He}$ fusions $\quad=8.68 \times 10^{19}$ per target

- Transmutation reactions:

$\mathrm{D}(\mathrm{n}, \gamma) \mathrm{T}$

$=4.85 \times 10^{16}$ tritons created $\rightarrow 80 \%$ immediately burn

$\mathrm{T}(\mathrm{n}, 2 \mathrm{n}) \mathrm{D}$

$=2.45 \times 10^{17}$ tritons destroyed

${ }^{3} \mathrm{He}(\mathrm{n}, \mathrm{p}) \mathrm{T}$

$=1.92 \times 10^{19}$ tritons created

- Overall tritium breeding:

Initial tritium $\quad=3.11 \times 10^{19}$ tritons/target

Final tritium

$=4.31 \times 10^{19}$ tritons/target

Tritium-lean target breeding ratio $=1.38$

Table 1.1 Tritium-balance for tritium-lean target [3]. 


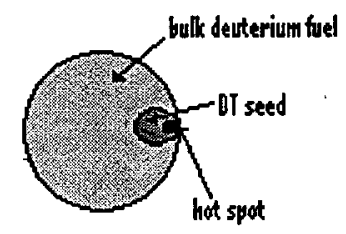

Figure 1.1 Sketch of a typical tritium-lean fuel assembly [4].
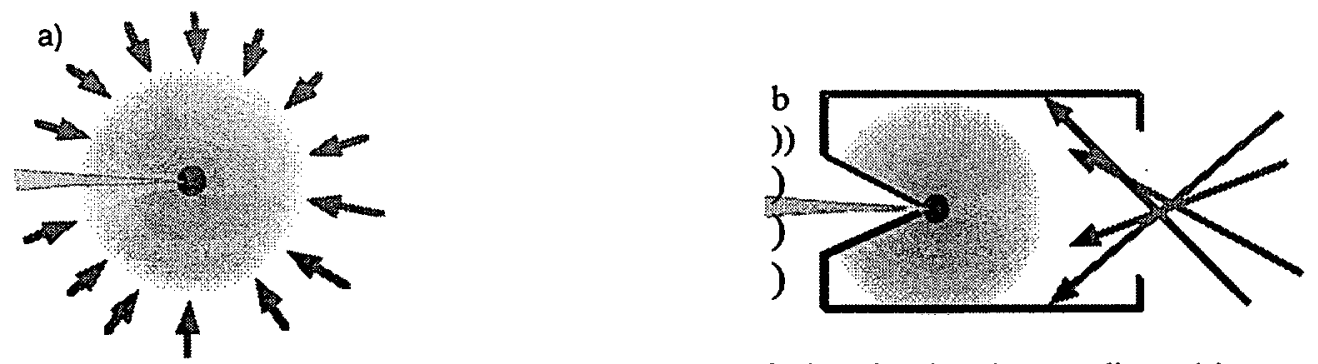

Figure 1.2 Sketch of possible methods of igniting tritium-lean fuels. Sketch a shows a direct-drive system with equal illumination from all angles surrounding target and the ignitor laser from the left. Sketch $b$ shows compression beams entering hohlraum from right, and ignitor laser from left $[6,17]$.

Traditionally, when designing a thick-liquid protected fusion energy chamber such as HYLIFE-II [XX], a major limitation to the choice of the liquid was the tritium-breeding ratio (TBR). The blanket was required to provide a TBR of greater than approximately 1.1 so that tritium did not need to be added to the system during operation. Elimination of this requirement allows for greater flexibility in a thick-liquid selection than ever before. Very little known work has been done suggesting a molten-salt that did not have a requirement of tritium breeding. Materials may now be selected based upon other characteristics, such as: safety and environmental characteristics, pumping power, corrosion, and vapor pressure, along with others.

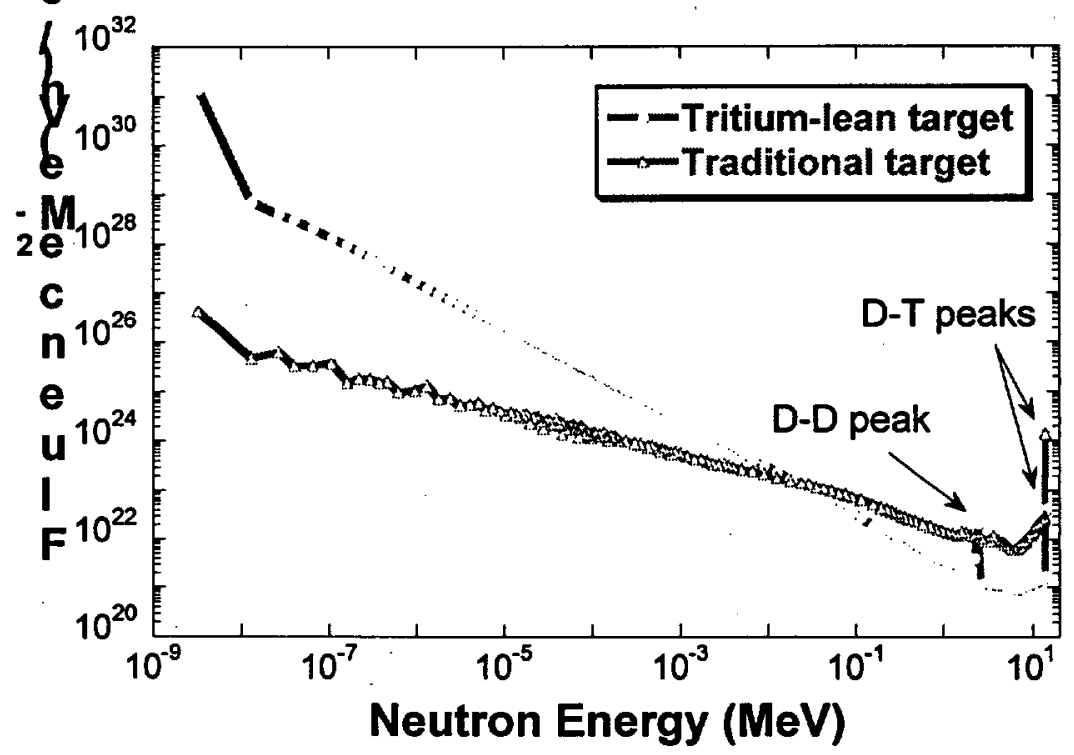

Fig. 1.3 Neutron spectrum emerging from a traditional deuterium-tritium target as well as the tritium-lean target analyzed by Atzeni $[4,5]$. 
This study assesses characteristics of single, binary, and ternary molten-salts as well as several liquid metals. Using the National Institute of Standards and Technology (NIST) Properties of Molten Salts Database, approximately 4300 molten-salts are included in the study [1]. Two rounds of analysis were performed and are reported herein. An assessment of the safety and environmental characteristics and a pumping power analysis are both performed on all materials with available density and viscosity data (necessary data for pumping power analysis). Viscosity data is taken for all materials at $900 \mathrm{~K}$.

\section{Safety and Environmental Assessment}

When considering a liquid for use in a fusion chamber, the safety and environmental characteristics are extremely important. Three assessments were done in this study: a calculation of the waste-disposal rating to determine if the material could meet the lowlevel waste criterion, an analysis of the radioactive afterheat as an indicator of the acceptability of the material from an accident perspective, and a calculation of the contact dose rate to determine if the material could be recycled following its use in the power plant. All analyses assumed a total inventory of material of approximately $1250 \mathrm{~m}^{3}$, with approximately $12.5 \mathrm{~m}^{3}$ (or $1 \%$ ) of the material in the chamber at any given time. All studies were done using the Monte Carlo code TART and the activation code ACAB $[8,9,10]$. Neutron irradiation was assumed to occur for 30 full-power years. To simplify the modeling, the neutron spectrum used for neutron activation calculations was that experienced by a 1-cm-thick shell of liquid. We applied this un-attenuated spectrum to the entire liquid blanket to give a model. Analysis was done for all elements on this shell. This conservative assumption was used only for the S\&E analyses.

\section{Waste-Disposal Rating}

A waste-disposal rating is given to a material in order to classify the method of disposal needed. The waste-disposal rating is given by :

$$
W D R=\sum_{i} \frac{A_{i} / V}{S A L_{i}},
$$

where $A_{i}$ is the activity of the $i^{\text {th }}$ radionuclide, SAL is its specific activity limit given by Fetter, Cheng, and Mann, and V is the component volume in $\mathrm{m}^{3}$ [11].

If the summation of all the radionuclides is taken, a comparison of each component is provided. If the WDR of the component is less than or equal to 1 , the material can be disposed of via shallow land burial. Given the potentially large waste volumes involved, disposal via shallow land burial is a primary goal for S\&E, and thus, liquids with a WDR greater than unity were eliminated from consideration. 


\section{Radioactive Afterheat}

In the case of a severe accident, the radioactive afterheat of the liquid could heat the chamber wall and increase the quantity of material mobilized and released to the environment. We compare the afterheat of the liquid to that from the chamber itself (assumed to be type 304 stainless steel, as in HYLIFE-II).

Results of radioactive afterheat were taken as an integrated afterheat after 7 days. Since only $1 \%$ of the liquid is in the chamber at any given time, we compare $1 \%$ of the total liquid integrated afterheat to that of the full chamber. Liquids in which the afterheat exceeds that of the chamber were eliminated. According to work done by S. Reyes et al., the temperature of the first wall of the chamber, in an accident scenario, varies only slightly for our time scales. As Figure 2.1 shows, there is a slight peak of temperature at approximately 15 minutes, and from then on (for the first day) the temperature of the wall decreases [12]. Figure 2.1 shows many reactor components, however we are most interested in the first wall result.

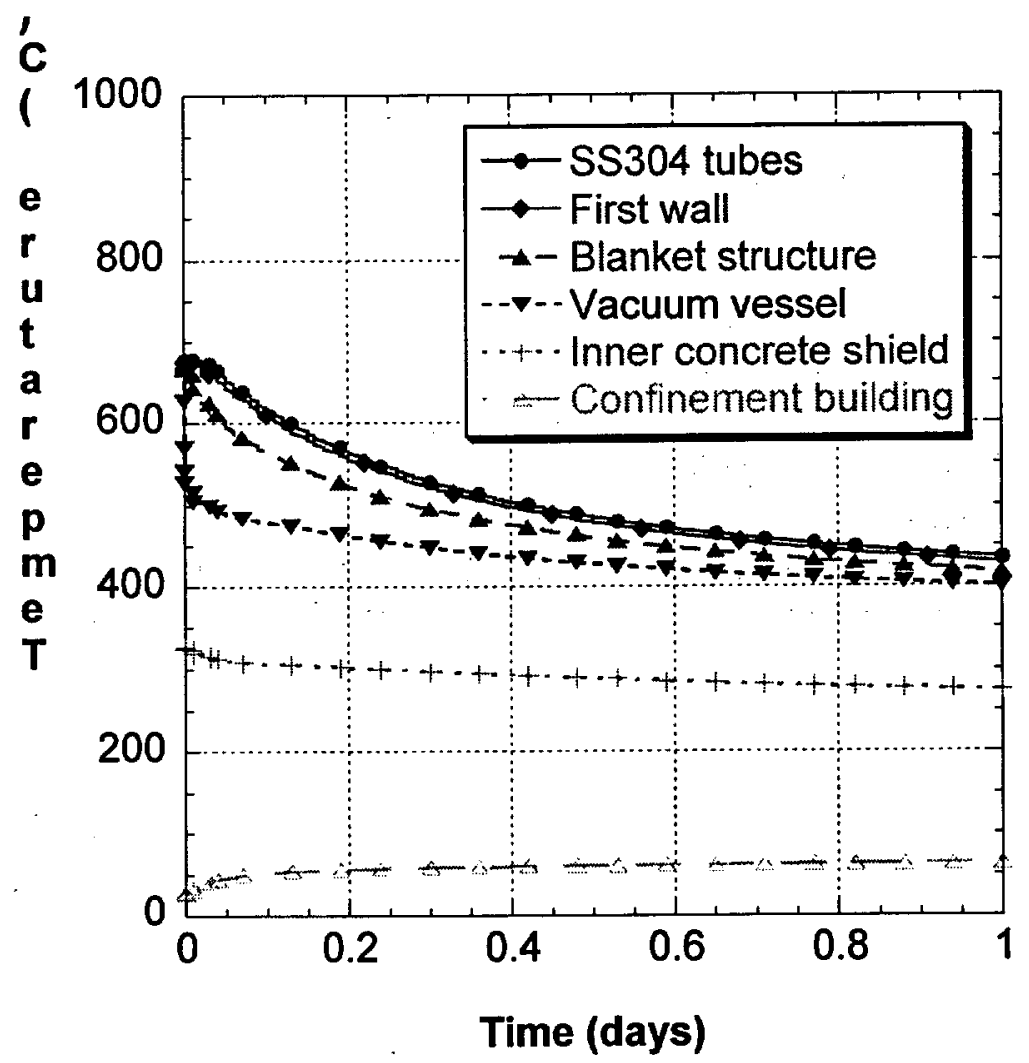

Figure 2.1 Temperature of Reactor Components at different times after accident [12]

In order to keep the SS 304 below its melting temperature $\left(\mathrm{T}_{\text {melt, }} \mathrm{ss} 304 \sim 1400^{\circ} \mathrm{C}\right)$, our integrated afterheat, at a time of 7 days after accident, must be below $2.33 \mathrm{E} 9 \mathrm{~W}$ 


\section{Contact Dose Rate}

The ability to recycle neutron-activated components is another S\&E criterion. Specifically, we assume that activated components qualify for remote recycling (e.g., robotic handling) provided that their contact dose limit is $<0.1 \mathrm{~Sv} / \mathrm{hr}$ following 50 years of radioactive decay. While hands-on recycling is desirable, it requires a significantly lower contact dose rate of $<25 \mu \mathrm{Sv} / \mathrm{hr}$, which may prove to be overly restrictive. Use of the remote recycling assumption allows a larger number of materials to be considered at this early stage of analysis.

\section{$S \& E$ Results}

A Fortran program was written to input a molten-salt (with the mole percent of each component) and calculate the density of each element in the material. These densities were then compared against the limits (based on S\&E criteria) for each element. If all of the elements included in a particular material were present at densities less than or equal to the density limit for that element, then the material passed the S\&E screening. Table 2.1 shows the acceptable limits of an element in a molten-salt, and which criterion limits the acceptability. For each material that contained one or more unacceptable elements, the output lists those elements along with the reason for elimination. This helped us better understand the acceptability of each individual element for S\&E characteristics. After assessing S\&E characteristics, there were approximately 200 liquids remaining-mostly single-salts and binaries. These were then evaluated for pumping power. 


\begin{tabular}{|c|c|c|}
\hline Element & $\begin{array}{l}\text { Limit } \\
\text { (g/cc) }\end{array}$ & $\begin{array}{l}\text { Limiting } \\
\text { Factor }\end{array}$ \\
\hline $\mathbf{L i}$ & 1.10E+02 & $\mathrm{AH}$ \\
\hline $\mathrm{Be}$ & $7.53 E+03$ & WDR \\
\hline B & $9.49 \mathrm{E}+02$ & WDR \\
\hline c & $8.34 E+01$ & WDR \\
\hline$N$ & 4.78E-02 & WDR \\
\hline 0 & $2.63 E+01$ & WDR \\
\hline $\mathbf{F}$ & $1.05 E+02$ & WDR \\
\hline $\mathrm{Ne}$ & $1.22 E+01$ & WDR \\
\hline $\mathrm{Na}$ & $5.11 E+01$ & CDR \\
\hline $\mathrm{Mg}$ & $2.64 E+01$ & $\mathrm{AH}$ \\
\hline $\mathrm{Al}$ & 3.45E-02 & WDR \\
\hline $\mathrm{Si}$ & $6.90 E+01$ & WDR \\
\hline$P$ & $3.72 E+02$ & $\mathrm{AH}$ \\
\hline$S$ & $2.06 \mathrm{E}+01$ & $\mathrm{AH}$ \\
\hline $\mathrm{Cl}$ & 4.90E-02 & WDR \\
\hline Ar & $6.45 E-02$ & WDR \\
\hline$K$ & $5.01 E-02$ & WDR \\
\hline $\mathrm{Ca}$ & $1.34 \mathrm{E}+00$ & WDR \\
\hline Sc & $5.09 \mathrm{E}+00$ & $\mathrm{AH}$ \\
\hline $\mathrm{Ti}$ & $5.86 E+01$ & $\mathrm{AH}$ \\
\hline V & $3.78 E+02$ & $\mathrm{AH}$ \\
\hline $\mathrm{Cr}$ & $1.41 E+03$ & $\mathrm{AH}$ \\
\hline Mn & $1.46 \mathrm{E}+01$ & $\mathrm{AH}$ \\
\hline $\mathrm{Fe}$ & $4.54 E+01$ & CDR \\
\hline Co & 7.13E-04 & CDR \\
\hline $\mathrm{Ni}$ & 1.02E-01 & CDR \\
\hline
\end{tabular}

\begin{tabular}{|c|c|c|}
\hline Element & $\begin{array}{l}\text { Limit } \\
\text { (g/cc) }\end{array}$ & $\begin{array}{l}\text { Limiting } \\
\text { Factor }\end{array}$ \\
\hline $\mathrm{Cu}$ & $1.85 \mathrm{E}-01$ & CDR \\
\hline $\mathrm{Zn}$ & $2.29 \mathrm{E}+01$ & CDR \\
\hline $\mathrm{Ga}$ & $8.48 E+00$ & $\mathrm{AH}$ \\
\hline $\mathrm{Ge}$ & $1.18 E+02$ & $\mathrm{AH}$ \\
\hline As & $2.51 E+00$ & $\mathrm{AH}$ \\
\hline Se & 5.51E-02 & WDR \\
\hline $\mathrm{Br}$ & 1.13E-01 & WDR \\
\hline $\mathrm{Kr}$ & 2.63E-01 & CDR \\
\hline $\mathrm{Rb}$ & $3.11 \mathrm{E}+00$ & CDR \\
\hline Sr & $7.29 E+01$ & CDR \\
\hline$Y$ & $8.38 E+00$ & $\mathrm{AH}$ \\
\hline $\mathrm{Zr}$ & $2.77 E+00$ & WDR \\
\hline $\mathrm{Nb}$ & 1.81E-05 & WDR \\
\hline Mo & 3.32E-04 & WDR \\
\hline $\mathbf{R u}$ & 7.41E-03 & WDR \\
\hline Rh & $3.54 E-02$ & WDR \\
\hline$P d$ & 2.05E-03 & WDR \\
\hline $\mathrm{Ag}$ & $9.04 E-05$ & WDR \\
\hline $\mathrm{Cd}$ & $2.88 E-02$ & WDR \\
\hline $\ln$ & $2.05 E+01$ & $A H$ \\
\hline Sn & $1.63 E+01$ & WDR \\
\hline $\mathrm{Sb}$ & $2.00 E+00$ & $\mathrm{AH}$ \\
\hline Te & $9.69 \mathrm{E}-01$ & WDR \\
\hline 1 & $2.90 E+01$ & $A H$. \\
\hline $\mathrm{Xe}$ & 9.83E-02 & CDR \\
\hline Cs & 1.43E-02 & CDR \\
\hline
\end{tabular}

\begin{tabular}{|c|c|c|}
\hline Element & $\begin{array}{l}\text { LImit } \\
\text { (g/cc) }\end{array}$ & $\begin{array}{l}\text { Limiting } \\
\text { Factor }\end{array}$ \\
\hline $\mathrm{Ba}$ & $8.66 E-02$ & CDR \\
\hline La & 1.15E+01 & WDR \\
\hline $\mathrm{Ce}$ & $1.29 \mathrm{E}+01$ & WDR \\
\hline $\mathrm{Pr}$ & $3.18 E+01$ & $\mathrm{AH}$ \\
\hline Nd & 9.82E-02 & CDR \\
\hline $\mathrm{Sm}$ & 7.78E-04 & CDR \\
\hline $\mathrm{Eu}$ & 4.76E-05 & CDR \\
\hline Gd & $9.26 E-04$ & WDR \\
\hline Tb & 2.66E-05 & WDR \\
\hline Dy & $1.60 \mathrm{E}-04$ & WDR \\
\hline Ho & 3.75E-06 & WDR \\
\hline $\mathrm{Er}$ & 4.64E-04 & WDR \\
\hline $\mathrm{Tm}$ & $1.35 E-02$ & WDR \\
\hline $\mathrm{Yb}$ & $1.64 E+01$ & WDR \\
\hline Lu & $1.49 E+01$ & $\mathrm{AH}$ \\
\hline $\mathrm{Hf}$ & $1.25 \mathrm{E}+01$ & $\mathrm{AH}$ \\
\hline $\mathrm{Ta}$ & $1.25 \mathrm{E}+00$ & $\mathrm{AH}$ \\
\hline$w$ & $8.38 E+00$ & WDR \\
\hline $\mathrm{Re}$ & 4.93E-01 & WDR \\
\hline Os & $6.45 E-03$ & WDR \\
\hline Ir & $9.80 E-05$ & WDR \\
\hline Pt & 7.33E-02 & WDR \\
\hline $\mathrm{Au}$ & $4.97 E+00$ & $\mathrm{AH}$ \\
\hline $\mathrm{Hg}$ & $2.04 E+02$ & $\mathrm{AH}$ \\
\hline TI & $3.35 E+01$ & $\mathrm{AH}$ \\
\hline $\mathrm{Pb}$ & $9.05 E+00$ & WDR \\
\hline $\mathbf{B i}$ & 5.15E-04 & WOR \\
\hline
\end{tabular}

Table 2.1 Maximum density an element can have in a liquid in order to be acceptable for use in thick-liquid protection of the fusion chamber.

Factor limiting element density:

$W D R=$ Waste Disposal Rating, $C D R=$ Contact Dose Rate

$A H=$ Radioactive Afterheat

\section{Pumping Power Assessment}

When considering a molten-salt for thick-liquid protection of a fusion chamber, the pumping power needed to pump the volume of material through the chamber is a very important characteristic in the selection of materials. Pumping power must be sufficiently low in order to maximize net electric power generated from the fusion plant. In the case of HYLIFE-II design, three components to pumping power must be considered: velocity head, frictional/minor losses in pipes, and lifting power. Velocity Head 
The molten-salt is delivered via oscillating nozzles in order to achieve a "pocket" for the target to be injected/ignited. This pocket must be thick enough to provide adequate shielding to chamber structure components.

Knowing that an equivalent thickness of flibe $\left(34 \% \mathrm{BeF}_{2}-66 \% \mathrm{LiF}\right)(56 \mathrm{~cm})$ will provide adequate shielding to the first wall of the chamber, by limiting neutron damage to less than 100 displacements per atom (DPA) after 30 years of continuous irradiation, we determined the thickness of each molten-salt that would result in an equivalent DPA. This equivalent thickness leads to, along with the mean free path (obtained from the Monte Carlo simulation code TART), the number of mean free paths the neutrons would need to be adequately diminished.

In this study, the chamber was assumed to be a spherical shell with inner radius of 0.5 meters. The volume of the liquid blanket can be estimated by the equation:

$$
\mathrm{V} \propto \frac{4}{3} \cdot \pi \cdot\left[\left(R_{p}+n_{s} \cdot \lambda_{n}\right)^{3}-R_{p}^{3}\right],
$$

where $R_{p}$ is the inner radius of the molten-salt pocket, $\lambda_{n}$ is the mean free path of the neutron -- at an energy of $2.539 \mathrm{MeV}$ (mean energy of Atzeni target) -- and $n_{s}$ is the number of mean free paths of liquid needed to adequately shield the chamber wall. For HYLIFE-II with traditional deuterium-tritium targets, we require a thickness of $56 \mathrm{~cm}$. This yields a blanket volume of $\sim 4.5 \mathrm{~m}^{3}$.

The actual volume of the molten-salt used in the chamber is $V_{c}=V \Omega$, where $\Omega$ is a geometric factor that adjusts for the complexity of the actual liquid blanket (a spherical shell is only an approximation). Given that the actual volume of flibe in HYLIFE-II is $12.5 \mathrm{~m}^{3}, \Omega$ is calculated to be 2.8 for our assumed geometry

The height of the blanket is taken to be:

$h=2 \cdot\left(R_{p}+\lambda_{n} \cdot n_{s}\right)$

Multiplying this height by the repetition rate yields the liquid injection velocity, $u$, needed to clear the chamber in time for the next "shot". This analysis neglects gravitational effects.

Figure 3.1 Depiction of the liquid pocket geometry in HYLIFE-II [13].

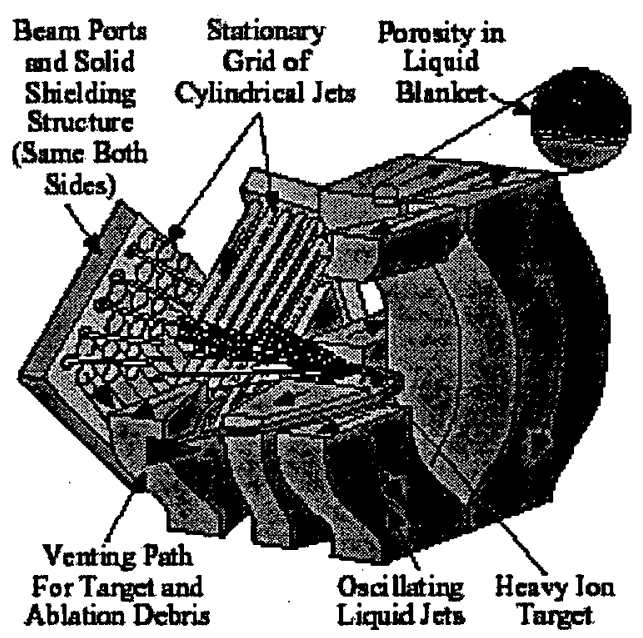


Starting from the first principles relation for power, we can derive a relation for the velocity head pumping power:

$$
\begin{aligned}
& P=E / t \\
& P=\frac{1}{2} m u^{2} \cdot f \\
& P=\frac{1}{2} \cdot V_{c} \cdot \rho \cdot u^{2} \cdot f,
\end{aligned}
$$

where $\rho$ is the liquid density (in $\mathrm{kg} / \mathrm{m}^{3}$ ), $u$ is the liquid velocity (in $\mathrm{m} / \mathrm{s}$ ), and $f$ is the frequency of shot repetition. Then, from Eqs. (3-1) and (3-2), we can obtain the velocity head pumping power:

$$
P=\frac{4}{6} \cdot \pi \cdot\left[\left(R_{p}+n_{s} \cdot \lambda_{n}\right)^{3}-R_{p}^{3}\right]\left[\left(2 \cdot\left(R_{p}+\lambda_{n} \cdot n_{s}\right)\right) \cdot f\right] \cdot \rho \cdot f
$$

\section{Frictional/Minor Losses}

With a liquid flowing through the piping of the structure, frictional losses are to be expected, and pumping power is needed to overcome these losses. A frictional factor is calculated using the Reynolds number for the flow. The Reynolds number was calculated using the equation [14]:

$$
\operatorname{Re}=\frac{u \cdot N_{d} \cdot \rho}{\eta},
$$

where $N_{d}$ is the thickness of the nozzle (assumed to be $7 \mathrm{~cm}$ ), and $\eta$ is the viscosity of the material (in $\mathrm{kg} / \mathrm{m}-\mathrm{s}$ ).

For turbulent flow $(\operatorname{Re}>3000)$, the friction factor is taken to be [14]:

$$
F=\frac{1.325}{\left[\ln \left(\frac{E_{d}}{3.7}+\frac{5.74}{\mathrm{Re}^{0.9}}\right)\right]^{2}},
$$

where $E_{d}$ is the value for the relative roughness of the pipe divided by the diameter of the pipe (in this study $E_{d}=1.5 E-5$ ).

For laminar flow $(\operatorname{Re}<3000)$, the friction factor is taken to be:

$$
F=\frac{64}{\operatorname{Re}}
$$


In order to calculate the pumping power due to frictional losses, an effective piping length is needed. Since our calculations were assuming straight pipes, corrections for bends, joints, etc. were made with an effective length (L/D)eff. This number is calculated as:

$$
(L / D)_{e f f}=\frac{2 \cdot g \cdot 7.5}{F_{\text {hylife-II }} \cdot Q_{\text {hylife-II }}^{2}},
$$

where $F_{\text {hylife-II }}$ is the frictional factor of the original HYLIFE-II flibe flow and $Q_{\text {hylife-II }}$ is the volumetric flow rate of flibe in the original design. For this study $(\mathrm{L} / \mathrm{D})_{\mathrm{eff}}=361$.

The pumping power needed to overcome frictional losses in the pipe is described by the equation:

$$
P=H \cdot \rho \cdot g \cdot Q \quad,
$$

where $H$ is the frictional head loss and is given by Eqn. 3-9.

$$
H=\text { head loss }=\frac{\frac{1}{2} \cdot F_{f} \cdot(L / D)_{e f f} \cdot u_{\text {pipe }}{ }^{2}}{g} .
$$

The frictional losses for the original HYLIFE-II design, with a traditional 50-50 D-T target, as described by Palmer House are 7.84 MW [15].

Use of the Atzeni target significantly reduces the required flow rate. This is mostly due to the lower repetition rate $(1.7 \mathrm{vs} .6 .4 \mathrm{~Hz})$, which reduces the liquid velocity. The softer spectrum of the Atzeni target also leads to a thinner pocket $(45 \mathrm{~cm}$ vs. $56 \mathrm{~cm})$ and the overall frictional losses are only $1.83 \mathrm{MW}$.

\section{Lifting Power}

Pumping power is needed to get the liquid that has been sprayed to the bottom of the chamber back up to the top of the chamber. This pumping power is called lifting power. It is calculated using a 10.5-meter distance from the bottom of the chamber to the top of the nozzle jets. The equation for the lifting power is given by:

$$
P=10.5 \cdot \rho \cdot g \cdot Q
$$

For the original HYLIFE-II design, the lift power was $10.98 \mathrm{MW}$. Using the values for the tritium-lean target results in a significant drop in the lifting pumping power to 4.68 MW (for flibe). In this case, the reduction is due entirely to the reduced flow rate. 
Sixty-six liquids were analyzed for the total pumping power needed to keep the salt flowing through the chamber at the correct frequency. Acceptable pumping power was assumed to be less than or equal to $80 \mathrm{MW}$, though the exact value is subject to debate. Nine liquids failed the pumping power requirement. Seven of the nine materials that failed contained boron, an extremely viscous material. The other two materials are $\mathrm{BeF}_{2}$ and $\mathrm{Tl}_{2} \mathrm{~S}$, both very viscous materials. Materials that fared well in the pumping power assessment usually contained lithium, sodium, or rubidium. Some other materials also pass, but on a less frequent basis. Some typical pumping power results are shown in Table 3.1. 


\begin{tabular}{|c|c|c|c|c|c|}
\hline Material \#1 & BeF2 & $\mathrm{Hgl2}$ & LiF & LiF & LiF \\
\hline Material \#2 & LiF & $\sim$ & $\sim$ & NaF & $\mathrm{NaF}$ \\
\hline Material \#3 & - & $\sim$ & $\sim$ & BeF2 & BeF2 \\
\hline Mol \%1 & 34.00 & 100 & 100 & 33.3 & 31.5 \\
\hline Mol \%2 & 66.00 & 0 & 0 & 33.3 & 31 \\
\hline Mol $\% 3$ & 0.00 & 0 & 0 & 33.4 & 37.5 \\
\hline Mean Free Path $(\mathrm{m})$ & 0.0450 & 0.1033 & 0.0349 & 0.0518 & 0.0512 \\
\hline Required Thickness (m) & 0.45 & 1.00 & 0.32 & 0.51 & 0.50 \\
\hline Density $\left(\mathrm{kg} / \mathrm{m}^{\wedge} \mathrm{3}\right)$ & 1974.00 & 4032 & 1917 & 2000 & 2000 \\
\hline Viscosity (kg/m-s) & $9.90 \mathrm{E}-03$ & $5.04 \mathrm{E}-04$ & $3.40 \mathrm{E}-03$ & $1.00 \mathrm{E}-02$ & $7.80 \mathrm{E}-02$ \\
\hline Velocity Head (MW) & 0.15 & 3.40 & 0.06 & 0.21 & 0.20 \\
\hline Frictional Losses (MW) & 1.83 & 6.93 & 0.94 & 2.19 & 3.61 \\
\hline Lift (MW) & 4.68 & 15.11 & 3.93 & 5.05 & 5.00 \\
\hline Pumping Power Total (MW) & 6.66 & 25.43 & 4.93 & 7.45 & 8.81 \\
\hline Normalized P.P. * & 1.00 & 3.82 & 0.74 & 1.12 & 1.32 \\
\hline Material \#1 & LiF & LiF & NaBF4 & NaF & PbF2 \\
\hline Material \#2 & NaF & NaF & $\sim$ & - & $\sim$ \\
\hline Material \#3 & BeF2 & $\sim$ & $\sim$ & $\sim$ & $\sim$ \\
\hline Mol \%1 & 63 & 60 & 100 & 100 & 100 \\
\hline Mol \%2 & 5 & 40 & 0 & 0 & 0 \\
\hline Mol \%3 & 32 & 0 & 0 & 0 & 0 \\
\hline Mean Free Path $(m)$ & 0.0463 & 0.0544 & 0.0464 & 0.0601 & 0.0401 \\
\hline Required Thickness (m) & 0.45 & 0.49 & 0.43 & 0.56 & 0.44 \\
\hline Density $\left(\mathrm{kg} / \mathrm{m}^{\wedge} \mathrm{3}\right)$ & 2000 & 2033 & 1792 & 2183 & 8200 \\
\hline Viscosity (kg/m-s) & $1.00 \mathrm{E}-02$ & $4.19 \mathrm{E}-03$ & 1.15E-03 & $4.11 \mathrm{E}-03$ & $1.00 \mathrm{E}-03$ \\
\hline Velocity Head (MW) & 0.15 & 0.19 & 0.12 & 0.29 & 0.59 \\
\hline Frictional Losses (MW) & 1.85 & 1.74 & 1.04 & 2.20 & 3.80 \\
\hline Lift (MW) & 4.75 & 5.03 & 4.16 & 5.75 & 19.25 \\
\hline Pumping Power Total (MW) & 6.75 & 6.97 & 5.32 & 8.24 & 23.64 \\
\hline Normalized P.P. & 1.01 & 1.05 & 0.80 & 1.24 & 3.55 \\
\hline Material \#1 & Li17Pb83 & LI & $\mathrm{Hg}$ & BeF2 & B2O3 \\
\hline Material \#2 & $\sim$ & $\sim$ & $\sim$ & $\sim$ & $\sim$ \\
\hline Material \#3 & $\sim$ & $\sim$ & $\sim$ & - & $\sim$ \\
\hline Mol \%1 & 100 & 100 & 100 & 100.00 & 100 \\
\hline Mol \%2 & 0 & 0 & 0 & $\sim$ & 0 \\
\hline Mol \%3 & 0 & 0 & 0 & $\sim$ & 0 \\
\hline Mean Free Path $(\mathrm{m})$ & 0.0494 & 0.1138 & 0.0340 & 0.0513 & 0.0583 \\
\hline Required Thickness (m) & 0.97 & 1.05 & 0.47 & 0.60 & 0.42 \\
\hline Density $\left(\mathrm{kg} / \mathrm{m}^{\wedge} 3\right)$ & 9710 & 530 & 13530 & 1959.00 & 1610 \\
\hline Viscosity $(\mathrm{kg} / \mathrm{m}-\mathrm{s})$ & $2.00 \mathrm{E}-03$ & $3.43 E-04$ & 1.45E-03 & $2.76 \mathrm{E}+04$ & $1.57 \mathrm{E}+02$ \\
\hline Velocity Head (MW) & 7.38 & 0.53 & 1.16 & 0.33 & 0.10 \\
\hline Frictional Losses (MW) & 17.38 & 1.17 & 6.76 & 454692.41 & 1809.25 \\
\hline Lift (MW) & 35.66 & 2.05 & 32.78 & 5.38 & 3.70 \\
\hline Pumping Power Total (MW) & 60.41 & 3.75 & 40.69 & 454698.13 & 1813.05 \\
\hline Normalized P.P. & 9.07 & 0.56 & 6.11 & 68272.99 & 272.23 \\
\hline
\end{tabular}

Table 3.1

Sample of Results of Pumping Power Assessment *Values normalized to flibe $\left(34 \% \mathrm{BeF}_{2}-66 \% \mathrm{LiF}\right)$ 


\section{Conclusions and Recommendations}

Upon conclusion of the numerical analysis, approximately 57 liquids passed all evaluations. Most of these salts contain elements such as sodium, lithium, beryllium, boron, fluorine, and oxygen. Other elements were present in lesser frequency. These liquids are presented in Table 4.1.

\begin{tabular}{|c|c|c|c|c|c|c|c|c|c|c|c|}
\hline \multicolumn{3}{|c|}{ Molten-Salt Composition } & \multicolumn{3}{|c|}{ Mol \% } & \multicolumn{3}{|c|}{ Molten-Salt Composition } & \multicolumn{3}{|c|}{ Mol \% } \\
\hline BeF2 & LiF & $\sim$ & 34 & 66 & 0 & $\mathrm{NaPO} 3$ & $\mathrm{Na2SO}$ & $\sim$ & 75 & 25 & 0 \\
\hline BeF2 & LiF & 〜 & 50 & 50 & 0 & $\mathrm{NaPO} 3$ & Na4P2O7 & $\sim$ & 75 & 25 & 0 \\
\hline BeF2 & LiF & 〜 & 75 & 25 & 0 & $\mathrm{NaVO} 3$ & $\sim$ & $\sim$ & 100 & 0 & 0 \\
\hline Bef2 & NaF & $\sim$ & 30 & 70 & 0 & NavO3 & V205 & $\sim$ & 20 & 80 & 0 \\
\hline BeF2 & NaF & $\sim$ & 50 & 50 & 0 & Navo3 & V205 & - & 80 & 20 & 0 \\
\hline BeF2 & RbF & $\sim$ & 50 & 50 & 0 & $\mathrm{Na} 2 \mathrm{CO} 3$ & - & $\sim$ & 100 & 0 & 0 \\
\hline $\mathrm{CaSO} 4$ & $\mathrm{Na} 2 \mathrm{SO} 4$ & $\sim$ & 10 & 90 & 0 & $\mathrm{Na2SO} 4$ & $\sim$ & $\sim$ & 100 & 0 & 0 \\
\hline CaSO4 & $\mathrm{Na2SO} 4$ & $\sim$ & 30 & 70 & 0 & $\mathrm{Na2S3}$ & $\sim$ & $\sim$ & 100 & 0 & 0 \\
\hline $\mathrm{CaSO}_{4}$ & $\mathrm{Na2SO} 4$ & $\sim$ & 55 & 45 & 0 & Na2S4 & $\sim$ & $\sim$ & 100 & 0 & 0 \\
\hline FeS & $\sim$ & 〜 & 100 & 0 & 0 & Na2S5 & $\sim$ & $\sim$ & 100 & 0 & 0 \\
\hline Hgl2 & 〜 & $\sim$ & 100 & 0 & 0 & Na2WO4 & $\sim$ & $\sim$ & 100 & 0 & 0 \\
\hline LiF & $\sim$ & $\sim$ & 100 & 0 & 0 & $\mathrm{Na4P2O7}$ & $\sim$ & $\sim$ & 100 & 0 & 0 \\
\hline LiF & $\mathrm{NaF}$ & BeF2 & 33.3 & 33.3 & 33.4 & $\mathrm{Na4P2O} 7$ & WO3 & $\sim$ & 34 & 66 & 0 \\
\hline LiF & $\mathrm{NaF}$ & BeF2 & 31.5 & 31 & 37.5 & Na4P2O7 & WO3 & $\sim$ & 65 & 35 & 0 \\
\hline LiF & NaF & BeF2 & 63 & 5 & 32 & RbF & $\sim$ & $\sim$ & 100 & 0 & 0 \\
\hline LiF & $\mathrm{NaF}$ & $\sim$ & 60 & 40 & 0 & Rbl & $\sim$ & $\sim$ & 100 & 0 & 0 \\
\hline LiF & RbF & $\sim$ & 43 & 57 & 0 & $\mathrm{Rb} 2 \mathrm{CO} 3$ & $\sim$ & $\sim$ & 100 & 0 & 0 \\
\hline LiI & $\sim$ & $\sim$ & 100 & 0 & 0 & TII & $\sim$ & $\sim$ & 100 & 0 & 0 \\
\hline $\mathrm{Li} 2 \mathrm{CO} 3$ & $\sim$ & $\sim$ & 100 & 0 & 0 & V2O5 & $\sim$ & 〜 & 100 & 0 & 0 \\
\hline $\mathrm{Li} 2 \mathrm{CO}_{3}$ & $\mathrm{Na} 2 \mathrm{CO} 3$ & $\sim$ & 10 & 90 & 0 & PbF2 & 〜 & - & 100 & 0 & 0 \\
\hline $\mathrm{Li} 2 \mathrm{CO} 3$ & $\mathrm{Na} 2 \mathrm{CO} 3$ & $\sim$ & 40 & 60 & 0 & $\mathbf{R b}$ & 〜 & $\sim$ & 100 & 0 & 0 \\
\hline $\mathrm{Li} 2 \mathrm{CO}_{3}$ & $\mathrm{Na} 2 \mathrm{CO} 3$ & $\sim$ & 60 & 40 & 0 & Li17Pb83 & $\sim$ & $\sim$ & 100 & 0 & 0 \\
\hline $\mathrm{Li} 2 \mathrm{CO} 3$ & $\mathrm{Na} 2 \mathrm{CO} 3$ & 〜 & 90 & 10 & 0 & $\mathrm{Na}$ & $\sim$ & & 100 & 0 & 0 \\
\hline LLI2WO4 & $\sim$ & $\sim$ & 100 & 0 & 0 & LI & $\sim$ & $\sim$ & 100 & 0 & 0 \\
\hline NaBF4 & $\sim$ & $\sim$ & 100 & 0 & 0 & $\mathbf{H g}$ & $\sim$ & $\sim$ & 100 & 0 & 0 \\
\hline NaBF4 & $\mathrm{NaF}$ & $\sim$ & 92 & 8 & 0 & $\mathrm{Ga}$ & $\sim$ & $\sim$ & 100 & 0 & 0 \\
\hline $\mathrm{NaF}$ & $\sim$ & $\sim$ & 100 & 0 & 0 & LISn & $\sim$ & $\sim$ & 100 & 0 & 0 \\
\hline Nal & $\sim$ & 〜 & 100 & 0 & 0 & In & 〜 & $\sim$ & 100 & 0 & 0 \\
\hline NaPO3 & $\sim$ & $\sim$ & 100 & 0 & 0 & & & & & & \\
\hline
\end{tabular}

Table 4.1 Liquids that passed all assessments.

It is recommended that further analysis be done on these liquids. Further analysis may include corrosion, surface tension, and/or vapor pressure assessments. After additional screening, perhaps 6-12 materials might remain. A detailed analysis of these materials then could be conducted to assess their suitability for use in a thick-liquid, fast ignition inertial confinement fusion energy system. 


\section{Acknowledgements}

The authors would like to thank Ralph W. Moir (LLNL) for his help in the overall development of this report. His collaboration has been essential to the completion of the above work. Work was performed under the auspices of the US Department of Energy by University of California Lawrence Livermore National Laboratory under Contract W7405-Eng-48.

\section{References}

1. NIST Properties of Molten Salts Database, Version 2, U. S. Dept. of Commerce, National Institute of Standards and Technology, January 1992.

2. M. Tabak, J. Hammer, M. E. Glinsky, W. L. Kruer, S. C. Wilks, J. Woodworth, E. M. Campbell, and M. D. Perry, "Ignition and high gain with ultra powerful lasers", Phys. Plasmas 1 (5), (May 1994).

3. J. F. Latkowski, B. G. Logan, L. J. Perkins, W. R. Meier, R. W. Moir, S. Atzeni, J. Sanz, "Safety and Environmental Advantages of Using TritiumLean Targets for Inertial Fusion Energy," Proceedings of the First International Conference on Inertial Fusion Sciences and Applications (Mar. 2000) 823-826.

4. S. Atzeni and M. L. Ciampi, "Burn performance of fast ignited, tritium-poor ICF fuels", Nucl. Fusion 37 (1997) 1665-1677.

5. S. Atzeni and M. L. Ciampi, "Potentiality of tritium-poor fuels for ICF fast ignitors", Fus. Eng. Des. 44 (1999) 225-231.

6. J. F. Latkowski, W. R. Meier, L. J. Perkins, S. Reyes, R. C. Schmitt, "Opportunities to Expand the IFE Chamber Parameter Space with Fast Ignition", to be submitted to IFSA 2001 conference, (2001).

7. Moir R. W. et al., "HYLIFE-II - A Molten-Salt Inertial Fusion Energy Power Plant Design - Final Report", Fusion Technology, (Jan. 1994), V25(N1):5-25.

8. J. F. Latkowski, "TARTREAD V1.0 User's Manual", Lawrence Livermore National Laboratory, UCRL-MA-122003 (1995).

9. D. E. Cullen, "TART98: A Coupled Neutron Photon 3-D, Combinatorial Geometry, Time Dependent, Monte Carlo Transport Code", LLNL, UCRLID-126455, Rev. 2 (1998).

10. J. Sanz, "ACAB98: Activation Code for Fusion Applications. User's Manual V4.0", Universidad Nacional de Educacion a Distancia (UNED), LLNL, UCRL-CR-133040 (1999).

11. S. A. Fetter, E. T. Cheng, and F. M. Mann, "Long-term radioactive waste from fusion reactors: Part II, Fusion Engineering and Design", 13, 239-246, (November 1990). 
12. S. Reyes, J. F. Latkowski, J. Gomez del Rio, J. Sanz, "Accident consequences analysis of the HYLIFE-II inertial fusion energy power plant design", Nuclear Instruments \& Methods in Physics Research, Section A, 416-421.

13. P. F. Peterson, "Design Methods for Thick-Liquid Protection of Inertial Fusion Chambers", Fusion Technology, 39, 702-710, (March, 2001).

14. B. R. Munson, D. F. Young, and T. H. Okiishi (1998) Fundamentals of Fluid Mechanics. Update Edition. John Wiley \& Sons, Inc.

15. P. A. House, "Hylife-II Reactor Chamber Design Refinements", Fusion Technology 26 (1994) 1178-1195.

16. J. F. Latkowski, "Inertial Fusion Energy: A Clearer View of the Environmental and Safety Perspectives", Lawrence Livermore National Laboratory Report, (November 1996).

17. R. B. Stephens, M. Key, W. Meier, R. Moir, and M. Tabak, "The Case for Fast Ignition as an IFE Concept Exploration Program", Proceedings of the 1999 Fusion Summer Study, Snowmass, CO (1999).

18. N. I. Sax and R. J. Lewis, Sr. (1987) Hawley's Condensed Chemical Dictionary. Eleventh Edition. Van Nostrand Reinhold Company.

19. R. C. Weast (1986) CRC Handbook of Chemistry and Physics. $67^{\text {th }}$ Edition. CRC Press, Inc. 